\title{
Factors associated with drinking behaviour during COVID-19 social distancing and lockdown among adults in the UK
}

\author{
Claire Garnett *, Sarah Jackson, Melissa Oldham, Jamie Brown, Andrew Steptoe, Daisy Fancourt \\ Department of Behavioural Science and Health, University College London, 1-19 Torrington Place, London, WC1E 7HB, UK
}

\section{A R T I C L E I N F O}

\section{Keywords:}

COVID-19

Alcohol

Drinking

Changes

UK

Drinkers

\begin{abstract}
A B S T R A C T
Background: To assess what factors were associated with reported changes to usual alcohol drinking behaviour during the start of lockdown in the United Kingdom (UK).

Methods: Online cross-sectional survey of 30,375 adults in the UK from 21st March to 4th April 2020 (sample weighted). Logistic regression models were used to examine sociodemographic, drinking and COVID-19 factors associated with i) drinking less and ii) drinking more (versus same as usual).

Results: Of 22,113 drinkers, $48.1 \%$ reported drinking about the same, $25.7 \%$ reported drinking less, and $26.2 \%$ reported drinking more than usual over the past week. Drinking less was independently associated with being younger ( $\mathrm{OR}=0.88, \mathrm{p}<.001)$, male ( $\mathrm{OR}=0.76, \mathrm{p}<.001)$, BAME (OR $=0.76, \mathrm{p}=.028)$, low income (OR $=$ 0.74, $\mathrm{p}<.001$ ), having COVID-19 (OR $=2.04, \mathrm{p}<.001$ ), adhering to COVID-19 protective behaviours (OR $=$ $1.58, \mathrm{p}=.020)$, stress about becoming ill from COVID-19 (OR $=1.26, \mathrm{p}=.004)$ and not being a key worker (OR $=0.87, \mathrm{p}=.030)$. Drinking more was independently associated with being younger $(\mathrm{OR}=0.73, \mathrm{p}<.001)$, female (OR $=1.36, \mathrm{p}<.001)$, post-16 qualifications $(\mathrm{OR}=1.21, \mathrm{p}=.012)$, high income $(\mathrm{OR}=1.43, \mathrm{p}<.001)$, stress about catching $(\mathrm{OR}=1.22, \mathrm{p}=.020)$ or becoming ill from COVID-19 (OR $=1.28, \mathrm{p}<.001)$, stress about finances $(\mathrm{OR}=1.43, \mathrm{p}<.001)$, and having an anxiety disorder $(\mathrm{OR}=1.24, \mathrm{p}=.011)$.

Conclusions: In a large, population sample of adults in the UK, around a quarter of drinkers reported drinking more alcohol and a quarter drinking less than usual during the COVID-19 related lockdown. Certain groups, such as those who are younger, female, of high socioeconomic position, have an anxiety disorder, and are stressed about finances or COVID-19 may need targeted alcohol reduction support during lockdown.
\end{abstract}

\section{Introduction}

COVID-19 is a respiratory disease that reached pandemic levels in March 2020 and was declared a Public Health Emergency of International Concern by the World Health Organisation. Reducing alcohol consumption remains a public health priority (Clay and Parker, 2020), and public health interventions have been highlighted as one way to "reduce the baseline" demand for acute healthcare services during the pandemic (Bhopal et al., 2020). Alcohol consumption is a leading risk factor for disease burden and the risk of all-cause mortality increases with increasing levels of consumption (GBD 2016 Alcohol Collaborators, 2018); 10.8 million adults in England drink at levels that pose some risk to their health (Public Health England, 2018). Establishing the factors associated with the immediate changes to usual drinking and heaviness of drinking during lockdown in the United Kingdom (UK) is important in order to tailor alcohol interventions to the COVID-19 context and target high-risk groups. This will also be particularly important if there is a second wave of COVID-19 and a return to national lockdown.

The UK response to the COVID-19 pandemic in March 2020 required significant disruption to people's lives. Government advice to practise social distancing came into effect on 16th March and behavioural restrictions (i.e. 'lockdown') enforceable by law were introduced on 23rd March. Many businesses, including pubs, bars and restaurants, were temporarily closed, and the public were advised to only leave their home for essential journeys and exercise. Early data have indicated that the COVID-19 pandemic has had an impact on people's alcohol consumption. A large, representative study of adults $(n>20,000)$ in England showed a substantial increase in the prevalence of high-risk drinking since the lockdown alongside an increase in attempts to reduce alcohol consumption among high-risk drinkers (Jackson et al., 2020). Other individual-level data suggest that the UK lockdown appeared to have a polarising effect on alcohol consumption. A survey of $\sim 2,000$ UK adults

\footnotetext{
* Corresponding author.

E-mail address: c.garnett@ucl.ac.uk (C. Garnett).
} 
commissioned by Alcohol Change UK conducted in early April found that $42 \%$ of drinkers had drunk less in the last two weeks compared with $13 \%$ who had drunk more (Alcohol Change UK, 2020). However, decreases in drinking were more likely among lighter drinkers and increases in drinking more likely among heavier drinkers (Alcohol Change UK, 2020). Generally, data are showing that between a fifth and a third of people in the UK have reported drinking more during lockdown, and that the proportion of people drinking less was often similar to or exceeding the proportion drinking more (CGA, 2020; Institute of Alcohol Studies, 2020).

Collectively, these studies provide evidence for changes in drinking behaviour since lockdown was introduced in the UK. However, there is currently limited evidence on what the sociodemographic risk factors that predict drinking behaviours during the pandemic are, but also whether there are any COVID-19 related risk factors, such as being a key worker or diagnosed COVID-19 (Institute of Alcohol Studies, 2020). It is critically important to understand who is drinking heavily or drinking more, and why, in order to effectively target support as there is a dose-response relationship between alcohol consumption and alcohol-related harms and the risk of mortality (Alcohol and Public Policy Group, 2010; GBD 2016 Alcohol Collaborators, 2018; Holmes et al., 2016). Furthermore, alcohol misuse can reduce immunity to viral infections and may increase the risk of severe illness from COVID-19 (Enos, 2020; Testino, 2020). There are a number of possible reasons people may be drinking more. The lockdown has resulted in people experiencing higher than normal levels of stress relating to social isolation, employment, finances, caring responsibilities, and concerns about catching or becoming ill from COVID-19 (Fancourt et al., 2020). Stress can have a polarising effect on drinking whereby people are more likely to either abstain or drink heavily under stressful conditions, rather than drink lightly or moderately (Jose et al., 2000). People who were drinking at harmful levels may develop alcohol dependence triggered by bereavement, job insecurity or troubled relationships during lockdown (Finlay and Gilmore, 2020). People may also drink more heavily to cope with boredom (Biolcati et al., 2016). A recent survey of $\sim 2,000$ adults in the UK found that $35 \%$ of furloughed workers were drinking more since lockdown compared with the population average of $24 \%$ (Drinkaware, 2020). It is also interesting to know who is drinking less and why, for example, because of health (CGA, 2020) or financial concerns (Cunningham et al., 2005) in the context of the pandemic.

In summary, there is a need for population-based evidence on the factors associated with changes to usual drinking and heaviness of drinking during COVID-19 related social distancing and lockdown in the UK. This study used cross-sectional data from a large well-phenotyped study of adults during the first few weeks of social distancing and lockdown in the UK to answer the following research questions:

1 Among drinkers, are perceived changes to usual drinking over the past week (more versus same as usual, and less versus same as usual) associated with sociodemographic characteristics, diagnosed or suspected COVID-19, adherence to COVID-19 protective behaviours, significant stress about catching or becoming seriously ill from COVID-19, significant stress about finances, significant stress about boredom, recent drop in household income, key worker status, or health conditions?

2 Is heaviness of drinking in the past week associated with sociodemographic characteristics, diagnosed or suspected COVID-19, adherence to COVID-19 protective behaviours, significant stress about catching or becoming seriously ill from COVID-19, significant stress about finances, significant stress about boredom, recent drop in household income, key worker status, or health conditions?

\section{Material and methods}

\subsection{Design and study population}

We carried out a cross-sectional analysis of baseline survey data from the University College London (UCL) COVID-19 Social Study assessing alcohol consumption and measures relating to COVID-19 in the UK for participants recruited between 21st March and 4th April 2020.

The UCL COVID-19 Social Study is a large panel study of the psychological and social experiences of adults (aged 18+) in the UK during the COVID-19 pandemic. The baseline survey from the study assessed a range of factors including sociodemographics, health, alcohol consumption, confirmed and suspected COVID-19, and behaviours and attitudes relating to COVID-19. Although participant recruitment was based on a multistage nonrandom sampling approach, the sample was designed to have broad representation across sociodemographic characteristics. Participants were recruited using three primary approaches. First, snowballing was used, including promoting the study through existing networks and mailing lists, print and digital media coverage, and social media. Second, more targeted recruitment was undertaken focusing on (i) individuals from a low-income background, (ii) individuals with no or few educational qualifications, and (iii) individuals who were unemployed. Third, the study was promoted via partnerships with third sector organisations to vulnerable groups, such as adults with pre-existing mental health conditions, and carers. The data are weighted to account for the non-random nature of the sample. For full details on the recruitment strategies and weighting for the study, visit www. covidsocialstudy.org.

\subsection{Measures}

\subsubsection{Changes in drinking over the past week}

Changes in drinking over the past week during social distancing and lockdown was measured with the question: "Over the past week have you drunk alcohol more than usual?" with response options: a) less than usual; b) about the same; c) more than usual; and d) I don't drink alcohol. Only drinkers (i.e. responses 'a', 'b' or 'c') were included in the analysis of changes in drinking. For analysis of drinking less or more than usual, those who responded ' $b$ ' were coded 0 and those who responded 'a' or 'c', respectively, were coded 1 .

\subsubsection{Heaviness of drinking in the past week}

Heaviness of drinking in the past week was assessed using the question: "How many alcoholic drinks have you had in the past week (e. g. how many glasses of wine / pints of beer or cider / shots of spirits)?" with continuous response options from ' 0 ' through to ' $21+$ '.

\subsubsection{Sociodemographic characteristics}

Sociodemographic characteristics included were: age (continuous in years), sex ( $\%$ female), ethnicity (\% white, versus Black, Asian and Minority Ethnic (BAME) groups), level of education (\% with post-16 qualifications; optional qualifications attained above the age of 16 e.g. A-levels, Scottish Highers, university degrees), and annual household income $(\%>£ 30,000$, in line with the median annual household income in the UK (Department for Work and Pensions, 2019)). Level of education and income were used as measures of socioeconomic position (SEP). Level of education provides a reliable indication of SEP prior to COVID-19 as it is not affected by recent job loss or furlough, and income gives a strong indication of the economic resources available to the participant and can influence a wide range of circumstances with direct implications for health (Galobardes et al., 2006).

\subsubsection{Diagnosed or suspected COVID-19}

Participants were asked: "Have you had COVID-19 (coronavirus)?" with response options a) yes diagnosed and recovered, b) yes diagnosed and still ill, c) not formally diagnosed but suspected, d) no. Diagnosed or 
suspected COVID-19 was coded 1 for those who responded 'a', 'b' or ' $c$ ' and 0 for those who responded ' $d$ '.

\subsubsection{Adherence to COVID-19 protective behaviours}

Adherence to COVID-19 protective behaviours was assessed with the question: "Are you following the recommendation from authorities to prevent spread of COVID-19?" with responses on a scale from 1 (not at all) to 7 (very much so). Responses of 5 and above were coded 1 (indicating adherence) and responses of 4 and below were coded 0 .

\subsubsection{Stress about COVID-19, finances or boredom}

Stress about COVID-19, finances or boredom was assessed with the question: "Have any of these things been causing you significant stress? (e.g. they have been constantly on your mind or have been keeping you awake at night)". Response options included i) catching COVID-19, ii) becoming seriously ill from COVID-19, iii) finances, and iv) boredom. For each of these four response options, a variable was created where those who reported stress about the relevant outcome were coded 1 , else they were coded 0 .

\subsubsection{Recent drop in household income}

Recent drop in household income was assessed with the question "Have you experienced any of the following in the past week?". Those who reported 'lost your job/been unable to do paid work', 'your spouse/ partner lost their job or was unable to do paid work' or 'major cut in household income (e.g. due to you or your partner being furloughed/put on leave/not receiving sufficient work)' were coded 1 for recent drop in household income and those who reported none of these were coded 0.

\subsubsection{Key worker status}

Key worker status may be associated with increased exposure to COVID-19. Participants were asked: "Are you currently fulfilling any of the government's identified 'key worker' roles?" Participants were coded 1 if they selected any of the 'key worker' roles (e.g. health care work, teacher, food chain worker) and those who responded 'none of these' were coded 0 .

\subsubsection{Health conditions}

The presence of health conditions was assessed with the question: "Do you have any of the following medical conditions?" Those who selected 'high blood pressure', 'diabetes', 'heart disease', 'lung disease (e.g. asthma or COPD)', or 'cancer' were coded 1 and those who selected none of these were coded 0 . These health conditions were included because people with these chronic conditions may be more likely to experience severe COVID-19 symptoms (Jordan et al., 2020; Onder et al., 2020). The presence of anxiety disorders was assessed with the same question, with those who selected 'clinically-diagnosed anxiety' coded 1 and those who did not select this response coded 0.

\subsubsection{Survey date}

Survey date was coded 0 for those surveys completed on 21st, 22nd or 23rd March (i.e. prior to lockdown commencing), and subsequent dates were coded $1,2,3, \ldots, n$ (i.e. reflecting the progression of time from the start of lockdown).

Full details of all of the measures is available in Supplementary File 1 .

\subsection{Analyses}

The protocol and analysis plan was pre-registered on Open Science Framework (https://osf.io/pnrhq/). Analyses were conducted using R studio on complete cases. To account for the non-random nature of the sample, all data were weighted to the proportions of sex, age, ethnicity, education, and country of living obtained from the Office for National Statistics (Office for National Statistics, 2018). Unweighted analyses are presented in supplementary material.
The proportion (and $95 \%$ confidence interval [CI]) of those who reported drinking more than usual, about the same as usual, and less than usual over the past week was calculated. The mean (and standard deviation [SD]) of heaviness of drinking in the past week was calculated.

Generalized linear modeling (logistic or linear, as appropriate) was used to examine unadjusted and adjusted associations of associations between i) drinking less than usual (versus about the same as usual), ii) drinking more than usual (versus about the same as usual), and iii) heaviness of drinking with the following: age, sex, ethnicity, education level, income, diagnosed or suspected COVID-19, adherence to COVID19 protective behaviours, significant stress about catching COVID-19, significant stress about becoming seriously ill from COVID-19, significant stress about finances, significant stress about boredom, recent drop in household income, key worker status, presence of health conditions and anxiety disorder, and survey date. The multivariable model was fully adjusted for all of the predictor variables listed. The continuous variable age was transformed by dividing the original variable by the SD to express the variable as a proportion of the SD for ease of interpretation of the odds ratio. Sensitivity analyses were conducted for the associations with heaviness of drinking where the response option ' $21+$ ' was excluded as this is a non-linear response option.

\subsection{Governance and ethics}

Ethical approval for the COVID-19 Social Study was granted by the UCL Ethics Committee [12467/005]. All participants provided fully informed consent. The study is GDPR compliant.

\section{Results}

\subsection{Participant characteristics}

A total of 33,644 participants responded to the survey between 21st March and 4th April 2020, of whom 30,375 (90.3\%; weighted $n=$ $30,516)$ provided complete data on the variables included in the present analyses. Of the analysed sample, 22,113 were drinkers $(65.7 \%$, weighted $n=21,212)$. Participant characteristics are shown in Table 1 (unweighted data are shown in Supplementary Table 1). The mean age was 47.8 years; around half were female ( $49.6 \%$ ) and had an annual household income over $£ 30,000$ (52.9\%); and the majority were white (88.0\%) and had post-16 education qualifications (69.3\%).

Table 1

Participant characteristics.

\begin{tabular}{ll}
\hline & $\begin{array}{l}\text { Whole sample } \\
\%(\mathrm{n}), \text { unless otherwise } \\
\text { stated }\end{array}$ \\
\hline Age, mean years (SD) & $47.8(16.36)$ \\
Female & $49.6(15,122)$ \\
White ethnicity & $88.0(26,850)$ \\
Post-16 education qualifications & $69.3(21,139)$ \\
Annual household income $>£ 30,000$ & $52.9(16,148)$ \\
Diagnosed or suspected COVID-19 & $9.1(2,788)$ \\
Adherence to COVID-19 protective behaviours & $96.9(29,297)$ \\
Significant stress about catching COVID-19 & $19.4(5,920)$ \\
Significant stress about becoming seriously ill from & $24.2(7,373)$ \\
$\quad$ COVID-19 & $19.9(6,059)$ \\
Significant stress about finances & $5.9(1,808)$ \\
Significant stress about boredom & $6.6(2,000)$ \\
Recent drop in household income & $23.3(7,114)$ \\
Key worker & $32.0(9,763)$ \\
Physical health conditions & $12.6(3,857)$ \\
Diagnosed anxiety disorder &
\end{tabular}

a Physical health conditions = one or more of high blood pressure, diabetes, heart or lung disease, or cancer. Note: All data are weighted to match the UK adult population on sex, age, ethnicity, education, and country of living. 


\subsection{Associations with changes in drinking over the past week}

Of the 22,113 drinkers (weighted $n=21,212), 48.1 \%(95 \% \mathrm{CI}=$ $47.0-49.1 \%$; weighted $n=10,196)$ reported drinking about the same as usual, $25.7 \%$ (95 \% CI $=24.8-26.6 \%$; weighted $n=5,451$ ) reported drinking less than usual, and $26.2 \%(95 \% \mathrm{CI}=25.4-27.1 \%$; weighted $n$ $=5,566$ ) reported drinking more than usual over the past week.

Drinking less than usual, compared with the same as usual, over the past week was independently associated with being younger, male, BAME, having an annual household income of less than $£ 30,000$, having diagnosed or suspected COVID-19, adhering to COVID-19 protective behaviours, being significantly stressed about becoming seriously ill from COVID-19, and not being a key worker (Table 2).

Drinking more than usual, compared with the same as usual, over the past week was independently associated with being younger, female, having post-16 education qualifications, having an annual household income over $£ 30,000$, being significantly stressed about catching or becoming seriously ill from COVID-19, being significantly stressed about finances, having a diagnosed anxiety disorder, and with survey date (Table 3).

Unweighted analyses are reported in Supplementary Tables 2 and 3 and the pattern of results is broadly similar.

\subsection{Associations with heaviness of drinking in the past week}

The mean heaviness of drinking in the past week was 4.0 alcoholic drinks ( $S D=5.34$ ). Heaviness of drinking in the past week was independently positively associated with being older, male, white ethnicity, having post-16 education qualifications, having an annual household income over $£ 30,000$, not adhering to COVID-19 protective behaviours, not being significantly stressed about catching COVID-19, a recent drop in household income, not being a key worker, not having physical health conditions or a diagnosed anxiety disorder, and with survey date (Table 4).

Sensitivity analyses were conducted in which the non-linear response option ' $21+$ ' was excluded (reported in Supplementary Table 4) and the pattern of results remained similar. Unweighted analyses are reported in Supplementary Table 5 and the pattern of results is broadly similar.

\section{Discussion}

Among a large, population sample of 30,375 adults in the UK surveyed in the first two weeks of national COVID-19 related social distancing and lockdown restrictions, adults drank a mean of 4 alcoholic drinks in the past week with almost a third not drinking (34.3\%). Among people who drank, $48 \%$ reported drinking about the same, $26 \%$ reported drinking more and $26 \%$ reported drinking less than usual over the past week. These findings are in line with those from other recent surveys (Institute of Alcohol Studies, 2020).

Younger drinkers were more likely than older drinkers to report changes in their drinking behaviour during lockdown (both drinking less and drinking more over the past week), which is consistent with previous findings (Portman Group, 2020; YouGov, 2020). Younger people in the UK may be drinking more because they have been most affected by lockdown with large declines in mental well-being being seen (Etheridge and Spantig, 2020), and the highest levels of loneliness and lowest levels of life satisfaction being reported (Fancourt and Steptoe, 2020). Younger people being more likely to drink less than usual may be attributable to the closure of on-trade drinking locations (e.g. bars and pubs) during the beginning of lockdown as on-trade drinking is more common among younger drinkers (Ally et al., 2016). This could also explain why older people's drinking remains relatively unaffected as they tend towards off-trade drinking and 'drinking at home alone' is more common among older people (Ally et al., 2016). However, heaviness of drinking was greater among older people at the start of lockdown, so it is important
Table 2

Factors associated with drinking less than usual, compared with same as usual, over the past week.

\begin{tabular}{|c|c|c|c|c|c|}
\hline & $\begin{array}{l}\text { Proportion } \\
\text { drinking less } \\
\text { than usual, } \\
\% \text { (n) }\end{array}$ & $\begin{array}{l}\text { Unadjusted } \\
\text { OR ( } 95 \% \\
\text { CI) }\end{array}$ & $\mathrm{p}$ & $\begin{array}{l}\text { Adjusted }^{\mathrm{b}} \\
\text { OR }_{\text {adj }} \\
(95 \% \mathrm{CI})\end{array}$ & $\mathrm{p}$ \\
\hline Age, in years & - & $\begin{array}{l}0.90(0.86, \\
0.95)\end{array}$ & $<.001$ & $\begin{array}{l}0.88 \\
(0.83, \\
0.93)\end{array}$ & $<.001$ \\
\hline Sex: Male & $36.5(3,249)$ & & & & \\
\hline Female & $32.7(2,201)$ & $\begin{array}{l}0.85(0.77 \\
0.93)\end{array}$ & $<.001$ & $\begin{array}{l}0.76 \\
(0.68, \\
0.84)\end{array}$ & $<.001$ \\
\hline Ethnicity: BAME & $41.7(680)$ & & & & \\
\hline White & $34.0(4,771)$ & $\begin{array}{l}0.72(0.57 \\
0.91)\end{array}$ & .005 & $\begin{array}{l}0.76 \\
(0.61, \\
0.97)\end{array}$ & .028 \\
\hline $\begin{array}{l}\text { Post-16 } \\
\text { education } \\
\text { qualifications: } \\
\text { No }\end{array}$ & $36.5(1,718)$ & & & & \\
\hline Yes & $34.1(3,733)$ & $\begin{array}{l}0.90(0.79 \\
1.02)\end{array}$ & .101 & $\begin{array}{l}0.90 \\
(0.79 \\
1.03)\end{array}$ & .135 \\
\hline $\begin{array}{l}\text { Annual } \\
\text { household } \\
\text { income: }< \\
£ 30,000\end{array}$ & $38.0(2,655)$ & & & & \\
\hline$>£ 30,000$ & $32.2(2,796)$ & $\begin{array}{l}0.78(0.70 \\
0.86)\end{array}$ & $<.001$ & $\begin{array}{l}0.74 \\
(0.66, \\
0.83)\end{array}$ & $<.001$ \\
\hline $\begin{array}{l}\text { Diagnosed or } \\
\text { suspected } \\
\text { COVID-19: No }\end{array}$ & $33.1(4,686)$ & & & & \\
\hline Yes & $50.9(765)$ & $\begin{array}{l}2.09(1.76, \\
2.48)\end{array}$ & $<.001$ & $\begin{array}{l}2.04 \\
(1.72, \\
2.41)\end{array}$ & $<.001$ \\
\hline $\begin{array}{l}\text { Adherence to } \\
\text { COVID-19 } \\
\text { protective } \\
\text { behaviours: No }\end{array}$ & $28.6(172)$ & & & & \\
\hline Yes & $35.1(5,279)$ & $\begin{array}{l}1.35(0.94 \\
1.94)\end{array}$ & .103 & $\begin{array}{l}1.58 \\
(1.08, \\
2.32)\end{array}$ & .020 \\
\hline $\begin{array}{c}\text { Significant stress } \\
\text { about catching } \\
\text { COVID-19: No }\end{array}$ & $34.1(4,490)$ & & & & \\
\hline Yes & 39.1 (961) & $\begin{array}{l}1.24(1.07 \\
1.44)\end{array}$ & .004 & $\begin{array}{l}1.01 \\
(0.84, \\
1.21)\end{array}$ & .941 \\
\hline $\begin{array}{l}\text { Significant stress } \\
\text { about } \\
\text { becoming } \\
\text { seriously ill } \\
\text { from COVID- } \\
\text { 19: No }\end{array}$ & $33.4(4,175)$ & & & & \\
\hline Yes & $40.6(1,276)$ & $\begin{array}{l}1.36(1.20 \\
1.55)\end{array}$ & $<.001$ & $\begin{array}{l}1.26 \\
(1.08, \\
1.48)\end{array}$ & .004 \\
\hline $\begin{array}{l}\text { Significant stress } \\
\text { about finances: } \\
\text { No }\end{array}$ & $34.0(4,468)$ & & & & \\
\hline Yes & 39.5 (984) & $\begin{array}{l}1.27(1.09 \\
1.47)\end{array}$ & .002 & $\begin{array}{l}1.02 \\
(0.87, \\
1.19)\end{array}$ & .829 \\
\hline $\begin{array}{l}\text { Significant stress } \\
\text { about } \\
\text { boredom: No }\end{array}$ & $34.4(5,109)$ & & & & \\
\hline Yes & $43.5(342)$ & $\begin{array}{l}1.47(1.12, \\
1.92)\end{array}$ & .005 & $\begin{array}{l}1.19 \\
(0.91, \\
1.57)\end{array}$ & .206 \\
\hline $\begin{array}{l}\text { Recent drop in } \\
\text { household } \\
\text { income: No }\end{array}$ & $34.4(5,076)$ & & & & \\
\hline Yes & $42.0(375)$ & $\begin{array}{l}1.38(1.10 \\
1.72)\end{array}$ & .005 & & .184 \\
\hline
\end{tabular}


Table 2 (continued)

\begin{tabular}{|c|c|c|c|c|c|}
\hline & $\begin{array}{l}\text { Proportion } \\
\text { drinking less } \\
\text { than usual, } \\
\%(n)\end{array}$ & $\begin{array}{l}\text { Unadjusted } \\
\text { OR (95\% } \\
\text { CI) }\end{array}$ & $\mathrm{p}$ & $\begin{array}{l}\text { Adjusted }^{\mathrm{b}} \\
\text { OR }_{\text {adj }} \\
(95 \% \text { CI })\end{array}$ & $\mathrm{p}$ \\
\hline & & & & $\begin{array}{l}1.17 \\
(0.93 \\
1.48)\end{array}$ & \\
\hline Key worker: No & $35.3(4,255)$ & & & & \\
\hline Yes & $33.2(1,196)$ & $\begin{array}{l}0.91(0.80, \\
1.03)\end{array}$ & .144 & $\begin{array}{l}0.87 \\
(0.76 \\
0.99)\end{array}$ & .030 \\
\hline $\begin{array}{l}\text { Physical health } \\
\text { conditions }^{\mathrm{a}} \text { : No }\end{array}$ & $34.5(3,669)$ & & & & \\
\hline Yes & $35.5(1,782)$ & $\begin{array}{l}1.04(0.93, \\
1.17)\end{array}$ & .464 & $\begin{array}{l}1.07 \\
(0.94 \\
1.21)\end{array}$ & .312 \\
\hline $\begin{array}{l}\text { Diagnosed } \\
\text { anxiety } \\
\text { disorder: No }\end{array}$ & $34.2(4,864)$ & & & & \\
\hline Yes & 40.7 (587) & $\begin{array}{l}1.32(1.10, \\
1.57)\end{array}$ & .002 & $\begin{array}{l}1.10 \\
(0.92 \\
1.32)\end{array}$ & .316 \\
\hline Survey date & - & $\begin{array}{l}1.02(1.00 \\
1.04)\end{array}$ & .051 & $\begin{array}{l}1.01 \\
(0.99 \\
1.03)\end{array}$ & .204 \\
\hline
\end{tabular}

Note: All data are weighted to match the UK adult population on sex, age, ethnicity, education, and country of living.

${ }^{\text {a }}$ Physical health conditions = high blood pressure, diabetes, heart or lung disease, or cancer.

b Multivariable model fully adjusted for all variables in the table.

that older drinkers are not overlooked in terms of alcohol reduction support during lockdown.

Women were more likely to report drinking more than usual and men were more likely to report drinking less than usual during lockdown. The latter finding is consistent with two previous surveys (Portman Group, 2020; YouGov, 2020). Women may be drinking more than men during lockdown because they have been more negatively affected by lockdown. Lockdown appears to have increased gender inequalities in both paid and unpaid work, with women more likely than men to lose their jobs and carry the burdens of increased childcare and housework (Craig and Churchill, 2020; Farré et al., 2020). There has also been a substantial negative effect of lockdown on mental well-being, which can lead to increased drinking. This negative effect on mental well-being is largely driven by women (Adams-Prassl et al., 2020; Etheridge and Spantig, 2020) due to family and caring responsibilities, and social factors such as increased loneliness (Etheridge and Spantig, 2020). Despite women being more likely to report drinking more than usual, heaviness of drinking in the past week during lockdown was positively associated with being male. However, this was also the case before lockdown began and despite a greater increase in women than men drinking at high risk in England during lockdown, the overall number is still greater for men (Public Health England, 2020a).

Drinkers with a low income were more likely to be drinking less than usual, whilst those with a high income and post-16 education qualifications were more likely to be drinking more than usual over the past week, and more heavily. Previous surveys have also found that a greater proportion of those of high SEP reported drinking more during lockdown than those of low SEP (YouGov, 2020). This is consistent with alcohol purchasing data for Great Britain which showed an increase in alcohol purchasing in all groups except those belonging to the lowest occupational and social grade and the largest increase among the more advantaged occupational groups (Public Health England, 2020b). Drinkers of high SEP may be drinking more than usual because they have more disposable income, and they tend to have more drinking occasions compared with drinkers of low SEP (Ally et al., 2016) and it may be that during lockdown there were more drinking occasions available. All of these findings taken together suggest that there is a
Table 3

Factors associated with drinking more than usual, compared with same as usual, over the past week.

\begin{tabular}{|c|c|c|c|c|c|}
\hline & $\begin{array}{l}\text { Proportion } \\
\text { drinking } \\
\text { more than } \\
\text { usual, \% (n) }\end{array}$ & $\begin{array}{l}\text { Unadjusted } \\
\text { OR (95\% } \\
\text { CI) }\end{array}$ & $\mathrm{p}$ & $\begin{array}{l}\text { Adjusted }^{\mathrm{b}} \\
\text { OR }_{\mathrm{adj}} \\
(95 \% \mathrm{CI})\end{array}$ & $\mathrm{p}$ \\
\hline Age, in years & - & $\begin{array}{l}0.66(0.63, \\
0.69)\end{array}$ & $<.001$ & $\begin{array}{l}0.73 \\
(0.69 \\
0.78)\end{array}$ & $<.001$ \\
\hline Sex: Male & $30.1(2,443)$ & & & & \\
\hline Female & $40.8(3,123)$ & $\begin{array}{l}1.60(1.44, \\
1.76)\end{array}$ & $<.001$ & $\begin{array}{l}1.36 \\
(1.22 \\
1.51)\end{array}$ & $<.001$ \\
\hline Ethnicity: BAME & $37.1(561)$ & & & & \\
\hline White & $35.1(5,004)$ & $\begin{array}{l}0.92(0.73, \\
1.15)\end{array}$ & .450 & $\begin{array}{l}1.08 \\
(0.84 \\
1.39)\end{array}$ & .555 \\
\hline $\begin{array}{l}\text { Post-16 } \\
\text { education } \\
\text { qualifications: } \\
\text { No }\end{array}$ & $28.6(1,194)$ & & & & \\
\hline Yes & $37.7(4,372)$ & $\begin{array}{l}1.51(1.32, \\
1.73)\end{array}$ & $<.001$ & $\begin{array}{l}1.21 \\
(1.04 \\
1.40)\end{array}$ & .012 \\
\hline $\begin{array}{l}\text { Annual } \\
\text { household } \\
\text { income: < } \\
£ 30,000\end{array}$ & $29.2(1,788)$ & & & & \\
\hline$>£ 30,000$ & $39.2(3,778)$ & $\begin{array}{l}1.56(1.40, \\
1.74)\end{array}$ & $<.001$ & $\begin{array}{l}1.43 \\
(1.27 \\
1.61)\end{array}$ & $<.001$ \\
\hline $\begin{array}{l}\text { Diagnosed or } \\
\text { suspected } \\
\text { COVID-19: No }\end{array}$ & $34.8(5,053)$ & & & & \\
\hline Yes & $40.9(512)$ & $\begin{array}{l}1.30(1.10, \\
1.54)\end{array}$ & .003 & $\begin{array}{l}1.06 \\
(0.89 \\
1.26)\end{array}$ & .517 \\
\hline $\begin{array}{l}\text { Adherence to } \\
\text { COVID-19 } \\
\text { protective } \\
\text { behaviours: No }\end{array}$ & $34.2(223)$ & & & & \\
\hline Yes & $35.4(5,342)$ & $\begin{array}{l}1.05(0.75, \\
1.48)\end{array}$ & .777 & $\begin{array}{l}0.89 \\
(0.61 \\
1.30)\end{array}$ & .553 \\
\hline $\begin{array}{l}\text { Significant stress } \\
\text { about catching } \\
\text { COVID-19: No }\end{array}$ & $33.6(4,405)$ & & & & \\
\hline Yes & $43.6(1,161)$ & $\begin{array}{l}1.53(1.34, \\
1.74)\end{array}$ & $<.001$ & $\begin{array}{l}1.22 \\
(1.03 \\
1.45)\end{array}$ & .020 \\
\hline $\begin{array}{l}\text { Significant stress } \\
\text { about } \\
\text { becoming } \\
\text { seriously ill } \\
\text { from COVID- } \\
\text { 19: No }\end{array}$ & $33.1(4,120)$ & & & & \\
\hline Yes & $43.6(1,446)$ & $\begin{array}{l}1.56(1.40, \\
1.75)\end{array}$ & $<.001$ & $\begin{array}{l}1.28 \\
(1.10 \\
1.48)\end{array}$ & $<.001$ \\
\hline $\begin{array}{l}\text { Significant stress } \\
\text { about finances: } \\
\text { No }\end{array}$ & $33.2(4,312)$ & & & & \\
\hline Yes & $45.4(1,254)$ & $\begin{array}{l}1.67(1.47, \\
1.90)\end{array}$ & $<.001$ & $\begin{array}{l}1.43 \\
(1.24, \\
1.66)\end{array}$ & $<.001$ \\
\hline $\begin{array}{l}\text { Significant stress } \\
\text { about } \\
\text { boredom: No }\end{array}$ & $34.8(5,215)$ & & & & \\
\hline Yes & $44.1(351)$ & $\begin{array}{l}1.47(1.15, \\
1.89)\end{array}$ & .002 & $\begin{array}{l}1.10 \\
(0.84 \\
1.44)\end{array}$ & .489 \\
\hline $\begin{array}{l}\text { Recent drop in } \\
\text { household } \\
\text { income: No }\end{array}$ & $34.3(5,060)$ & & & & \\
\hline Yes & $49.4(506)$ & $\begin{array}{l}1.87(1.54, \\
2.26)\end{array}$ & $<.001$ & & .055 \\
\hline
\end{tabular}


Table 3 (continued)

\begin{tabular}{|c|c|c|c|c|c|}
\hline & $\begin{array}{l}\text { Proportion } \\
\text { drinking } \\
\text { more than } \\
\text { usual, \% (n) }\end{array}$ & $\begin{array}{l}\text { Unadjusted } \\
\text { OR (95\% } \\
\text { CI) }\end{array}$ & $\mathrm{p}$ & $\begin{array}{l}\text { Adjusted }^{\mathrm{b}} \\
\text { OR }_{\text {adj }} \\
(95 \% \text { CI })\end{array}$ & $\mathrm{p}$ \\
\hline & & & & $\begin{array}{l}1.23 \\
(1.00 \\
1.51)\end{array}$ & \\
\hline Key worker: No & $34.6(4,128)$ & & & & \\
\hline Yes & $37.4(1,437)$ & $\begin{array}{l}1.13(1.01, \\
1.26)\end{array}$ & .032 & $\begin{array}{l}0.92 \\
(0.82 \\
1.03)\end{array}$ & .191 \\
\hline $\begin{array}{l}\text { Physical health } \\
\text { conditions }^{\mathrm{a}} \text { : No }\end{array}$ & $37.8(4,237)$ & & & & \\
\hline Yes & $29.1(1,328)$ & $\begin{array}{l}0.67(0.60 \\
0.75)\end{array}$ & $<.001$ & $\begin{array}{l}0.91 \\
(0.80 \\
1.03)\end{array}$ & .128 \\
\hline $\begin{array}{l}\text { Diagnosed } \\
\text { anxiety } \\
\text { disorder: No }\end{array}$ & $34.0(4,819)$ & & & & \\
\hline Yes & $46.6(747)$ & $\begin{array}{l}1.69(1.45, \\
1.96)\end{array}$ & $<.001$ & $\begin{array}{l}1.24 \\
(1.05 \\
1.46)\end{array}$ & .011 \\
\hline Survey date & - & $\begin{array}{l}1.07(1.06, \\
1.09)\end{array}$ & $<.001$ & $\begin{array}{l}1.06 \\
(1.04, \\
1.08)\end{array}$ & $<.001$ \\
\hline
\end{tabular}

Note: All data are weighted to match the UK adult population on sex, age, ethnicity, education, and country of living.

a Physical health conditions $=$ high blood pressure, diabetes, heart or lung disease, or cancer.

b Multivariable model fully adjusted for all variables in the table.

polarisation based on SEP in terms of how drinking behaviour has changed during lockdown. It is reassuring that these findings suggest that changes in drinking behaviour during lockdown have not widened existing alcohol-related health inequalities, as those of low SEP are more at risk of alcohol-related harm for the same level of consumption compared with those of high SEP (Bellis et al., 2016).

BAME groups were more likely than those of white ethnicity to be drinking less than usual. Being of white ethnicity was positively associated with heaviness of drinking, which is in line with previous surveys from before the COVID-19 pandemic (NHS Digital, 2018). Some BAME individuals who follow religions that encourage abstention may drink less. There is clear evidence that COVID-19 does not affect all groups equally and minority ethnic groups have a greater risk of infection, experience more severe symptoms and higher rates of death (Pan et al., 2020; Public Health England, 2020c). Therefore, minority ethnic groups being more likely to drink less than usual may be a response to more general health concerns in the context of the pandemic and protecting their long-term health by reducing their alcohol consumption (CGA, 2020; Cunningham et al., 2005). Similarly, those who had had diagnosed or suspected COVID-19 or were adhering to COVID-19 protective behaviours were more likely to report drinking less than usual over the past week, and adhering to protective behaviours was also negatively associated with heaviness of drinking. These groups are more likely to have COVID-19-related health concerns and therefore may be taking steps to protect their health by drinking less. Those who were not a key worker were more likely to be drinking less than usual, though not being a key worker was also positively associated with the heaviness of drinking.

We also found that psychological factors predicted changes in drinking behaviours. Stress about catching COVID-19, becoming seriously ill from COVID-19 and finances were all associated with drinking more than usual over the past week, and stress about catching COVID-19 and experiencing a recent drop in household income were also positively associated with heaviness of drinking. This is in line with previous research showing that stress is a risk factor for the onset of alcohol misuse (Jose et al., 2000; Uhart and Wand, 2009). However, stress about becoming seriously ill from COVID-19 was also associated with drinking
Table 4

Factors associated with heaviness of drinking in the past week.

\begin{tabular}{|c|c|c|c|c|c|}
\hline & $\begin{array}{l}\text { Mean } \\
\text { number of } \\
\text { drinks in } \\
\text { past week } \\
\text { (SD) }\end{array}$ & $\begin{array}{l}\text { Unadjusted } \\
\text { B (95 \% CI) }\end{array}$ & $\mathrm{p}$ & $\begin{array}{l}\text { Adjusted }^{\mathrm{b}} \\
\mathrm{B}_{\text {adj }}(95 \% \\
\mathrm{CI})\end{array}$ & $\mathrm{p}$ \\
\hline Age, in years & - & $\begin{array}{l}0.59(0.50, \\
0.68)\end{array}$ & $<.001$ & $\begin{array}{l}0.64 \\
(0.54 \\
0.75)\end{array}$ & $<.001$ \\
\hline Sex: Male & $4.8(5.92)$ & & & & \\
\hline Female & $3.2(4.54)$ & $\begin{array}{l}-1.61 \\
(-1.80 \\
-1.42)\end{array}$ & $<.001$ & $\begin{array}{l}-1.29 \\
(-1.47 \\
-1.10)\end{array}$ & $<.001$ \\
\hline Ethnicity: BAME & $2.3(3.97)$ & & & & \\
\hline White & $4.2(5.46)$ & $\begin{array}{l}1.85(1.54, \\
2.15)\end{array}$ & $<.001$ & $\begin{array}{l}1.67 \\
(1.36 \\
1.98)\end{array}$ & $<.001$ \\
\hline $\begin{array}{l}\text { Post-16 education } \\
\text { qualifications: } \\
\text { No }\end{array}$ & $3.6(5.30)$ & & & & \\
\hline Yes & $4.2(5.35)$ & $\begin{array}{l}0.59(0.36, \\
0.82)\end{array}$ & $<.001$ & $\begin{array}{l}0.61 \\
(0.38 \\
0.85)\end{array}$ & $<.001$ \\
\hline $\begin{array}{l}\text { Annual household } \\
\text { income: }< \\
£ 30,000\end{array}$ & $3.2(5.04)$ & & & & \\
\hline$>£ 30,000$ & $4.7(5.50)$ & $\begin{array}{l}1.46(1.27, \\
1.65)\end{array}$ & $<.001$ & $\begin{array}{l}1.53 \\
(1.32 \\
1.73)\end{array}$ & $<.001$ \\
\hline $\begin{array}{l}\text { Diagnosed or } \\
\text { suspected } \\
\text { COVID-19: No }\end{array}$ & $4.0(5.37)$ & & & & \\
\hline Yes & $3.6(5.03)$ & $\begin{array}{l}-0.36 \\
(-0.66 \\
-0.05)\end{array}$ & .023 & $\begin{array}{l}-0.10 \\
(-0.40 \\
0.20)\end{array}$ & .516 \\
\hline $\begin{array}{l}\text { Adherence to } \\
\text { COVID-19 } \\
\text { protective } \\
\text { behaviours: No }\end{array}$ & $4.6(6.50)$ & & & & \\
\hline Yes & $3.9(5.28)$ & $\begin{array}{l}-0.64 \\
(-1.36 \\
0.08)\end{array}$ & .083 & $\begin{array}{l}-0.96 \\
(-1.65 \\
-0.27)\end{array}$ & .006 \\
\hline $\begin{array}{l}\text { Significant stress } \\
\text { about catching } \\
\text { COVID-19: No }\end{array}$ & $4.2(5.40)$ & & & & \\
\hline Yes & $3.2(5.00)$ & $\begin{array}{l}-0.97 \\
(-1.20 \\
-0.74)\end{array}$ & $<.001$ & $\begin{array}{l}-0.31 \\
(-0.58 \\
-0.03)\end{array}$ & .029 \\
\hline $\begin{array}{l}\text { Significant stress } \\
\text { about becoming } \\
\text { seriously ill } \\
\text { from COVID-19: } \\
\text { No }\end{array}$ & $4.2(5.42)$ & & & & \\
\hline Yes & $3.3(5.01)$ & $\begin{array}{l}-0.91 \\
(-1.12 \\
-0.71)\end{array}$ & $<.001$ & $\begin{array}{l}-0.21 \\
(-0.45 \\
0.03)\end{array}$ & .084 \\
\hline $\begin{array}{l}\text { Significant stress } \\
\text { about finances: } \\
\text { No }\end{array}$ & $4.1(5.37)$ & & & & \\
\hline Yes & $3.3(5.18)$ & $\begin{array}{l}-0.79 \\
(-1.03 \\
-0.55)\end{array}$ & $<.001$ & $\begin{array}{l}-0.01 \\
(-0.26 \\
0.23)\end{array}$ & .916 \\
\hline $\begin{array}{l}\text { Significant stress } \\
\text { about boredom: } \\
\text { No }\end{array}$ & $4.0(5.34)$ & & & & \\
\hline Yes & $3.6(5.37)$ & $\begin{array}{l}-0.43 \\
(-0.87 \\
0.02)\end{array}$ & .060 & $\begin{array}{l}0.23 \\
(-0.20 \\
0.66)\end{array}$ & .286 \\
\hline $\begin{array}{l}\text { Recent drop in } \\
\text { household } \\
\text { income: No }\end{array}$ & $4.0(5.34)$ & & & & \\
\hline Yes & $4.0(5.40)$ & $\begin{array}{l}0.01 \\
(-0.38 \\
0.40)\end{array}$ & .967 & $\begin{array}{l}0.44 \\
(0.03 \\
0.84)\end{array}$ & .033 \\
\hline Key worker: No & $4.1(5.48)$ & & & & \\
\hline Yes & $3.6(4.85)$ & & $<.001$ & & .002 \\
\hline
\end{tabular}


Table 4 (continued)

\begin{tabular}{|c|c|c|c|c|c|}
\hline & $\begin{array}{l}\text { Mean } \\
\text { number of } \\
\text { drinks in } \\
\text { past week } \\
\text { (SD) }\end{array}$ & $\begin{array}{l}\text { Unadjusted } \\
\text { B (95 \% CI) }\end{array}$ & $\mathrm{p}$ & $\begin{array}{l}\text { Adjusted }^{\mathrm{b}} \\
\mathrm{B}_{\text {adj }}(95 \% \\
\text { CI) }\end{array}$ & $\mathrm{p}$ \\
\hline & & $\begin{array}{l}-0.47 \\
(-0.68 \\
-0.27)\end{array}$ & & $\begin{array}{l}-0.32 \\
(-0.52 \\
-0.12)\end{array}$ & \\
\hline $\begin{array}{l}\text { Physical health } \\
\text { conditions }{ }^{\mathrm{a}}: \text { No }\end{array}$ & $4.0(5.19)$ & & & & \\
\hline Yes & $4.0(5.65)$ & $\begin{array}{l}-0.003 \\
(-0.22 \\
0.21)\end{array}$ & .981 & $\begin{array}{l}-0.33 \\
(-0.56 \\
-0.10)\end{array}$ & .0049 \\
\hline $\begin{array}{l}\text { Diagnosed anxiety } \\
\text { disorder: No }\end{array}$ & $4.2(5.39)$ & & & & \\
\hline Yes & $2.7(4.78)$ & $\begin{array}{l}-1.44 \\
(-1.68 \\
-1.20)\end{array}$ & $<.001$ & $\begin{array}{l}-0.52 \\
(-0.76 \\
-0.28)\end{array}$ & $<.001$ \\
\hline Survey date & - & $\begin{array}{l}0.01 \\
(-0.02, \\
0.04)\end{array}$ & .572 & $\begin{array}{l}0.04 \\
(0.0003, \\
0.07)\end{array}$ & .048 \\
\hline
\end{tabular}

Note: All data are weighted to match the UK adult population on sex, age, ethnicity, education, and country of living.

a Physical health conditions = high blood pressure, diabetes, heart or lung disease, or cancer.

b Multivariable model fully adjusted for all variables in the table.

less than usual over the past week. This could be due to health and economic stress in the context of the pandemic (CGA, 2020; Cunningham et al., 2005); stress likely has a polarising effect whereby it motivates some people to cut down to improve health and others to drink heavily as a maladaptive coping strategy (Jose et al., 2000).

Exploring mental health more broadly, having a diagnosed anxiety disorder was associated with drinking more than usual though was negatively associated with heaviness of drinking, along with having a physical health condition. It is possible that people with anxiety disorders are changing their drinking behaviour to self-medicate (Bolton et al., 2006) or as a coping mechanism (Kuntsche et al., 2005) during a period of increased anxiety because of the pandemic. This finding fits with a recent survey where reasons for increased drinking during lockdown were commonly reported as being due to worry and depression (Winstock et al., 2020). This could indicate that people are drinking as a maladaptive coping mechanism and future research should investigate the motives behind changes in drinking behaviour among people with mental health conditions.

\subsection{Strengths and limitations}

A key strength of this study was the large sample size and broad range of measures collected, permitting this detailed analysis of potential factors predicting drinking behaviour during the start of social distancing and lockdown in the UK. The collection of data in real time while the pandemic was at a peak in late March and early April was also a strength, minimising potential recall bias that is likely to be present in any future studies that collect data retrospectively. Another major strength of this study was being able to assess how sociodemographic characteristics and COVID-19-related impacts, such as key worker status, were associated with changes in alcohol consumption - an important area of research highlighted in a recent report by the Institute of Alcohol Studies (Institute of Alcohol Studies, 2020).

A limitation of this study relates to the alcohol consumption measures used. The measure of changes in drinking over the past week did not distinguish between changes in frequency of consumption, quantity per occasion or heavy episodic drinking, which is an important topic for future research. Furthermore, the changes in drinking measure used the reference 'usual drinking' rather than specifying before lockdown. We have assumed that participants interpreted 'usual drinking' as meaning before lockdown restrictions were introduced as the study period was chosen as the start of social distancing and lockdown in the UK. The measure of heaviness of drinking asks about the number of alcoholic drinks consumed and therefore the overall index does not directly correspond with standardised units. As the survey was conducted at the start of lockdown and the heaviness of drinking measure refers to the past week, the associations detected may reflect the characteristics of people who were drinking alcohol more heavily prior to the COVID-19 pandemic rather than as a response to the lockdown in the UK. However, it was still important to consider the heaviness of drinking as this gives an important indication for the public health implications of respondents' alcohol consumption.

The study did not include a measure of baseline alcohol consumption, although it did ask about consumption in the previous week, which occurred before lockdown came in and focused on drinking behaviour during the first few weeks of lockdown in March 2020. Future studies with prior data may be able to ascertain how long-term trajectories of alcohol consumption were affected by the pandemic. Whilst we do not know the prevalence of high-risk drinking in this sample, our finding that $26 \%$ of adults in the UK reported drinking more could be reconciled with data on the change in high-risk drinking prevalence in England (Jackson et al., 2020), particularly if those who reported drinking more were borderline high-risk drinkers before lockdown.

\subsection{Implications}

This study has important implications in terms of groups that may need targeted support for alcohol reduction to counteract an increase in drinking during the start of the COVID-19 related lockdown. With one in four drinkers reporting an increase in consumption since lockdown began, these findings emphasise the need for alcohol reduction support with a focus on those groups who are drinking more than usual and drinking heavily. This may be particularly important if a second wave of COVID-19 results in another lockdown. However, more research is needed to understand whether these changes have been sustained or whether people's drinking have returned (or will return) to usual levels as they gradually resume their normal lives. Heaviness of drinking was positively associated with survey date indicating that heaviness of drinking increased with the time spent in lockdown, therefore it's important to establish whether any initial changes during the start of lockdown continued, or possibly were even exacerbated.

\section{Conclusions}

About half of adult drinkers in the UK reported drinking about the same as usual, a quarter reported drinking more than usual, and a quarter reported drinking less than usual over the past week during the start of the COVID-19 related lockdown. Drinking more than usual during the start of lockdown was associated with being younger, female, of high SEP, having an anxiety disorder, being stressed about finances, or being stressed about catching or becoming seriously ill from COVID19. This highlights that there are certain groups who need alcohol reduction support during lockdown and to whom it might be particularly important to target support for if there is a second wave of COVID19.

\section{Funding source}

The funders had no final role in the study design; in the collection, analysis and interpretation of data; in the writing of the report; or in the decision to submit the paper for publication. All researchers listed as authors are independent from the funders and all final decisions about the research were taken by the investigators and were unrestricted. 


\section{Contributors}

All authors conceptualised the study, and contributed to and approved the final version of the manuscript. CG drafted the manuscript and conducted the data analysis.

\section{Declaration of Competing Interest}

CG, SJ, MO, AS and DF declare no conflicts of interest. JB has received unrestricted research grants from Pfizer related to smoking cessation.

\section{Acknowledgements}

The Covid-19 Social Study was funded by the Nuffield Foundation [WEL/FR-000022583], but the views expressed are those of the authors and not necessarily the Foundation. The study was also supported by the MARCH Mental Health Network funded by the Cross-Disciplinary Mental Health Network Plus initiative supported by UK Research and Innovation [ES/S002588/1], and by the Wellcome Trust [221400/Z/ 20/Z]. DF was funded by the Wellcome Trust [205407/Z/16/Z]. CG is funded by CRUK [C1417/A22962] and NIHR. SJ and JB are funded by CRUK [C1417/A22962]. MO is funded by NIHR.

The researchers are grateful for the support of a number of organisations with their recruitment efforts including: the UKRI Mental Health Networks, Find Out Now, UCL BioResource, SEO Works, FieldworkHub, and Optimal Workshop. The study was also supported by HealthWise Wales, the Health and Car Research Wales initiative, which is led by Cardiff University in collaboration with SAIL, Swansea University.

\section{Appendix A. Supplementary data}

Supplementary material related to this article can be found, in the online version, at doi:https://doi.org/10.1016/j.drugalcdep.2020.10 8461.

\section{References}

Adams-Prassl, A., Boneva, T., Golin, M., Rauh, C., 2020. The impact of the coronavirus lockdown on mental health: evidence from the US. Cambridge Work. Pap. Econ., pp. 1-20.

Alcohol and Public Policy Group, 2010. Alcohol: no ordinary commodity-a summary of the second edition. Addiction 105, 769-779. https://doi.org/10.1111/j.13600443.2010.02945.x.

Alcohol Change UK, 2020. Drinking During Lockdown.

Ally, A.K., Lovatt, M., Meier, P.S., Brennan, A., Holmes, J., 2016. Developing a social practice-based typology of British drinking culture in 2009-2011: implications for alcohol policy analysis. Addiction 111, 1568-1579. https://doi.org/10.1111/ add.13397.

Bellis, M.A., Hughes, K., Nicholls, J., Sheron, N., Gilmore, I., Jones, L., 2016. The alcohol harm paradox: using a national survey to explore how alcohol may disproportionately impact health in deprived individuals. BMC Public Health 16, 111. https://doi.org/10.1186/s12889-016-2766-x.

Bhopal, S., Kaur Bola, G., Hughes, R., Gopfert, A., Bhopal, A., 2020. Can we improve the NHS's ability to tackle covid-19 through emergency public health interventions? BMJ Opin.

Biolcati, R., Passini, S., Mancini, G., 2016. "I cannot stand the boredom.” Binge drinking expectancies in adolescence. Addict. Behav. Rep. 3, 70-76. https://doi.org/10.1016/ J.ABREP.2016.05.001.

Bolton, J., Cox, B., Clara, I., Sareen, J., 2006. Use of alcohol and drugs to self-medicate anxiety disorders in a nationally representative sample. J. Nerv. Ment. Dis. 194, 818-825. https://doi.org/10.1097/01.nmd.0000244481.63148.98.

CGA, 2020. Britain's Drinking Habits Are Changing under Lockdown [WWW Document]. https://www.cga.co.uk/2020/04/03/britains-drinking-habits-are-changing-underlockdown/.

Clay, J.M., Parker, M.O., 2020. Alcohol use and misuse during the COVID-19 pandemic: a potential public health crisis? Lancet Public Heal. 5, e259. https://doi.org/10.1016/ S2468-2667(20)30088-8.

Craig, L., Churchill, B., 2020. Dual-earner parent couples' work and care during COVID19. Gender, Work Organ, pp. 1-14. https://doi.org/10.1111/gwao.12497.
Cunningham, J.A., Blomqvist, J., Koski-Jännes, A., Cordingley, J., 2005. Current heavy drinkers' reasons for considering change: results from a natural history general population survey. Addict. Behav. 30, 581-584. https://doi.org/10.1016/j. addbeh.2004.05.028.

Department for Work and Pensions, 2019. Households Below Average Income: An Analysis of the UK Income Distribution: 1994/95-2014/15.

Drinkaware, 2020. Furloughed Workers Drinking More on Lockdown [WWW Document]. https://www.drinkaware.co.uk/press/furloughed-workers-drinkingmore-on-lockdown/.

Enos, G., 2020. Effects on lung, immune function offer warning for drinking in crisis. Alcohol. Drug Abus. Wkly. 32, 1-8. https://doi.org/10.1002/adaw.32693.

Etheridge, B., Spantig, L., 2020. The gender gap in mental well-being during the Covid19 outbreak: evidence from the UK. Inst. Soc. Econ. Res. ISER Work. Pap. Ser. 8, 26.

Fancourt, D., Steptoe, A., 2020. Stress Related to Catching COVID-19 Is Highest Among 30-59 Year-olds [WWW Document]. UCL News. https://www.ucl.ac.uk/news/2020 /apr/stress-related-catching-covid-19-highest-among-30-59-year-olds.

Fancourt, D., Bu, F., Mak, H., Steptoe, A., 2020. Covid-19 Social Study: Results Release 1 [WWW Document]. https://746a1e8d-7231-4b96-9bc2-88b2eb5c4964.filesusr.co m/ugd/3d9db5 a82c3a15441f4687a0114efc78307e80.pdf.

Farré, L., Fawaz, Y., González, L., Graves, J., 2020. How the COVID-19 Lockdown Affected Gender Inequality in Paid and Unpaid Work in Spain.

Finlay, I., Gilmore, I., 2020. Covid-19 and alcohol—a dangerous cocktail. BMJ 369. https://doi.org/10.1136/BMJ.M1987.

Galobardes, B., Shaw, M., Lawlor, D.A., Lynch, J.W., Smith, G.D., 2006. Indicators of socioeconomic position (part 1). J. Epidemiol. Commun. Health 60, 7-12. https:// doi.org/10.1136/jech.2004.023531.

GBD 2016 Alcohol Collaborators, 2018. Alcohol use and burden for 195 countries and territories, 1990-2016: a systematic analysis for the Global Burden of Disease Study 2016. Lancet 392 (10152), 1015-1035. https://doi.org/10.1016/S0140-6736(18) 31310-2.

Holmes, J., Angus, C., Buykx, P., Ally, A., Stone, T., Meier, P., Brennan, A., 2016. Mortality and Morbidity Risks From Alcohol Consumption in the UK: Analyses Using the Sheffield Alcohol Policy Model (v.2.7) to Inform the UK Chief Medical Officers' Review of the UK Lower Risk Drinking Guidelines Final Report.

Institute of Alcohol Studies, 2020. Alcohol Consumption during the COVID-19 Lockdown.

Jackson, S., Garnett, C., Shahab, L., Oldham, M., Brown, J., 2020. Association of the Covid-19 lockdown with smoking, drinking, and attempts to quit in England: an analysis of 2019-2020 data. Addiction, 33089562. https://doi.org/10.1101/ 2020.05.25.20112656.

Jordan, R.E., Adab, P., Cheng, K.K., 2020. Covid-19: risk factors for severe disease and death. BMJ 368, m1198. https://doi.org/10.1136/bmj.m1198.

Jose, B.S., Van Oers, H.A.M., Van de Mheen, H.D., Garretsen, H.F.L., Mackenbach, J.P., 2000. Stressors and alcohol consumption. Alcohol Alcohol. 35, 307-312. https://doi. org/10.1093/alcalc/35.3.307.

Kuntsche, E., Knibbe, R., Gmel, G., Engels, R., 2005. Why do young people drink? A review of drinking motives. Clin. Psychol. Rev. 25, 841-861. https://doi.org/ 10.1016/j.cpr.2005.06.002

NHS Digital, 2018. Harmful and Probable Dependent Drinking in Adults.

Office for National Statistics, 2018. Population Estimates [WWW Document]. https ://www.ons.gov.uk/peoplepopulationandcommunity/populationandmigration/pop ulationestimates.

Onder, G., Rezza, G., Brusaferro, S., 2020. Case-fatality rate and characteristics of patients dying in relation to COVID-19 in Italy. JAMA 323, 1775-1776. https://doi. org/10.1001/jama.2020.4683.

Pan, D., Sze, S., Minhas, J.S., Bangash, M.N., Pareek, N., Divall, P., Williams, C.M., Oggioni, M.R., Squire, I.B., Nellums, L.B., Hanif, W., Khunti, K., Pareek, M., 2020 The impact of ethnicity on clinical outcomes in COVID-19: a systematic review. EClinicalMedicine 23. https://doi.org/10.1016/j.eclinm.2020.100404.

Portman Group, 2020. YouGov / Portman Group Survey on Alcohol Consumption during the COVID-19 Lockdown.

Public Health England, 2018. Health Matters: Harmful Drinking and Alcohol Dependence [WWW Document]. https://www.gov.uk/government/publications/health-matte rs-harmful-drinking-and-alcohol-dependence/.

Public Health England, 2020a. Behavioural Risk Factors: Alcohol Consumption [WWW Document]. https://analytics.phe.gov.uk/apps/covid-19-indirect-effects/.

Public Health England, 2020b. Wider Impacts of COVID-19 on Health Monitoring Tool [WWW Document]. gov.uk.

Public Health England, 2020c. Beyond the Data: Understanding the Impact of COVID-19 on BAME Groups.

Testino, G., 2020. Are Patients With Alcohol Use Disorders at Increased Risk for Covid-19 Infection? Alcohol Alcohol. 55, 344-346. https://doi.org/10.1093/alcalc/agaa037.

Uhart, M., Wand, G.S., 2009. Stress, alcohol and drug interaction: an update of human research. Addict. Biol. 14, 43-64. https://doi.org/10.1111/j.13691600.2008.00131.x.

Winstock, A., Davies, E., Gilchrist, G., Zhuparris, A., Ferris, J., Maier, L., Barratt, M., 2020. GDS Special Edition on Covid-19: Global Interim Report.

YouGov, 2020. Daily Question | 24/03/2020 | Are You Drinking More or Less Alcohol Than You Normally Would?. 